\title{
A COMPARISON OF THE ALLANTOIN AND INULIN CLEARANCES FOR THE MEASUREMENT OF FILTRATION RATE IN THE DISEASED HUMAN KIDNEY 1, 2
}

\author{
By BENJAMIN F. MILLER, 3 ALEXANDER LEAF,4 AUDLEY R. MAMBY, AND \\ ZELMA MILLER 5
}

(From the Children's Medical Service and the Department of Medicine, the Massachusetts General Hospital, and the Harvard Medical School, Boston, Massachusetts)

(Submitted for publication September 17, 1951 ; accepted January 8, 1952)

A substance capable of measuring filtration rate with the precision of inulin, but without its drawbacks, would be extremely helpful in measurements on the human kidney. A suitable compound would be one which is already present in the body or easily administered by mouth. Allantoin appeared to answer these requirements. Its renal clearance had been measured in rats and dogs by Friedman and Byers (1), and it seemed to provide a precise measure of filtration rate. When administered orally it is non-toxic and not too unpalatable. It is relatively inexpensive. Furthermore, the allantoin reaches an adequate concentration in the blood stream after approximately two hours, and this level remains fairly constant for a period of three hours (2).

Friedman, Byers and Abrahm therefore studied the clearance of allantoin in a group of normal human subjects and in patients suffering from cardiorenal diseases (3). They concluded from their experiments that the allantoin clearance offers a precise measure of filtration rate in patients with both normal and diseased kidneys.

It seemed to us important to repeat and extend these observations on the allantoin clearance, especially in the diseased kidney. We have assumed that the inulin clearance may be taken as the "referee" value, and have compared inulin and al-

1 Aided by grants from the Research Corporation, and the Bristol-Myers Company, New York City.

$2 \mathrm{~A}$ preliminary report of this work appeared in the Proceedings of the Forty-Third Annual Meeting of the American Society for Clinical Investigation, J. Clin. Invest., 1951, 30, 661.

3 Present address : Peter Bent Brigham Hospital, Boston, Massachusetts.

4 National Research Council Fellow in the Medical Sciences, 1949-1951.

5 Present address : Children's Cancer Research Foundation, Children's Medical Center, Boston, Massachusetts. lantoin clearances in nine patients with various types of renal lesions.

\section{METHODS}

The inulin clearance was obtained by the procedure described in the preceding paper (4). Allantoin clearances were performed as described by Friedman, Byers and Abrahm (3), and allantoin was determined according to their procedure. This is essentially the method of Christman, Foster and Esterer (5), with the incorporation of a modification proposed by Young and Conway (6). In our initial studies with this method, we obtained excellent recoveries of allantoin added to urine, but discouragingly erratic results with serum. This appeared to be caused by the use of full-strength Folin-Wu sodium tungstate and sulfuric acid reagents in the preparation of protein-free filtrates. Perfectly satisfactory results were obtained with half-strength reagents, employing $8 \mathrm{cc}$. of water, $0.5 \mathrm{cc}$. 10 per cent sodium tungstate and 0.5 cc. $2 / 3 \mathrm{~N} \mathrm{H}_{2} \mathrm{SO}_{4}$ for each cc. of serum. We have found the method accurate and reproducible, but exceedingly tedious and demanding when compared with the simplicity of creatinine or inulin determinations.

Blood samples were yeasted in all experiments, and urines were yeasted in one experiment on a diabetic patient.

To preclude the possibility of oxidation of uric acid to allantoin, blood sera and urines were kept in the frozen state until ready for analysis. They were analyzed immediately after the preparation of protein-free filtrates.

As indicated by Friedman and co-workers, uric acid yields about one-fifth as much color as allantoin. Allantoin values were therefore corrected for uric acid, which was determined by the method of Archibald (7).

\section{RESULTS AND DISCUSSION}

The inulin and allantoin clearances, and the allantoin/inulin ratios are presented in Table I. Simultaneous clearances of inulin and allantoin were obtained in 28 periods. In 11 comparisons the clearance ratios fell within 10 per cent of unity. In the others the deviations were greater. Seventeen clearance ratios of allantoin to inulin fell below 
0.9; the lowest was 0.64. Eight clearance ratios lay between 0.7 and 0.8 , and eight between 0.8 and 0.9 .

The deviations of clearance ratios were not related to renal function. Patient S. A. S. who had the poorest excretory function showed allantoin/ inulin ratios of $0.84,0.75$ and 0.77 , and patient B. M. who had the highest inulin clearance in the group gave clearance ratios of $0.73,0.75$, and 0.64 .

Low allantoin/inulin ratios were observed in patients with advanced organic disease of the kidney (S. A. S. and M. W.), as well as in patients with the reversible renal impairment of cardiac decompensation (A. L. and B. M.).

TABLE I

Comparison of inulin and allantoin clearances*

\begin{tabular}{|c|c|c|c|}
\hline \multirow{2}{*}{ Patient } & \multicolumn{2}{|c|}{ Allantoin } & \multirow{2}{*}{$\begin{array}{l}\text { Clearance ratio } \\
\text { allantoin/inulin }\end{array}$} \\
\hline & $\begin{array}{l}\text { Serum conc'n } \\
(m g . / 100 c c .)\end{array}$ & $\begin{array}{c}\text { Clearancet } \\
(c c . / \min .)\end{array}$ & \\
\hline S. A. S. & $\begin{array}{l}1.79 \\
1.85 \\
1.87\end{array}$ & $\begin{array}{r}10.0 \\
7.9 \\
8.9\end{array}$ & $\begin{array}{l}0.84 \\
0.75 \\
0.77\end{array}$ \\
\hline M. W. & $\begin{array}{l}5.7 \\
5.8 \\
6.2\end{array}$ & $\begin{array}{l}19.2 \\
17.3 \\
18.0\end{array}$ & $\begin{array}{l}0.86 \\
0.82 \\
0.81\end{array}$ \\
\hline R. P. & $\begin{array}{l}6.8 \\
7.0 \\
6.9 \\
6.7\end{array}$ & $\begin{array}{l}57.1 \\
56.9 \\
54.1 \\
56.6\end{array}$ & $\begin{array}{l}1.08 \\
1.04 \\
0.93 \\
0.97\end{array}$ \\
\hline A. $\mathbf{M}$. & $\begin{array}{l}5.4 \\
5.4 \\
5.5\end{array}$ & $\begin{array}{l}57.1 \\
56.0 \\
59.8\end{array}$ & $\begin{array}{l}1.01 \\
1.00 \\
1.08\end{array}$ \\
\hline A. J. & $\begin{array}{l}4.7 \\
4.8 \\
4.8\end{array}$ & $\begin{array}{l}69.9 \\
57.1 \\
63.0\end{array}$ & $\begin{array}{l}1.05 \\
0.98 \\
0.97\end{array}$ \\
\hline A. L. & $\begin{array}{l}4.6 \\
4.5 \\
4.5\end{array}$ & $\begin{array}{l}62.0 \\
65.9 \\
70.0\end{array}$ & $\begin{array}{l}0.79 \\
0.82 \\
0.85\end{array}$ \\
\hline J. R. & $\begin{array}{l}5.1 \\
5.4 \\
5.5\end{array}$ & $\begin{array}{l}79.0 \\
67.0 \\
66.5\end{array}$ & $\begin{array}{l}0.78 \\
0.76 \\
0.77\end{array}$ \\
\hline F. B. & $\begin{array}{l}6.4 \\
6.1 \\
5.7\end{array}$ & $\begin{array}{l}90.0 \\
77.3 \\
81.1\end{array}$ & $\begin{array}{l}0.87 \\
0.88 \\
0.94\end{array}$ \\
\hline B. $\mathrm{M}$. & $\begin{array}{l}2.6 \\
2.8 \\
3.1\end{array}$ & $\begin{array}{l}68.8 \\
82.1 \\
73.0\end{array}$ & $\begin{array}{l}0.73 \\
0.75 \\
0.64\end{array}$ \\
\hline
\end{tabular}

* See accompanying paper (4) for further details regarding these patients in whom the allantoin clearances were determined simultaneously with the inulin and creatinine clearances shown on p. 311 .

$\dagger$ All clearances are corrected for body surface area of 1.73 sq. meters.
It is interesting that when good agreement was obtained between the allantoin and inulin clearances all comparisons in the individual experiments were close to unity. For example, patient R. P. had ratios of 1.08, 1.04, 0.93, and 0.97; patient A. M., 1.01, 1.00, and 1.08; and patient A. J., ratios of $1.05,0.98$, and 0.97 . Unfortunately, we were not able to repeat the clearance experiments on any of the patients in the group to ascertain the degree of reproducibility of the clearance ratios at different times.

If allantoin behaved like inulin and were excreted entirely by filtration, the allantoin/inulin ratios should all approach unity. We have found this to be true in only three of nine experiments. The deviations of the allantoin clearance are all in the same direction, lower than inulin. This suggests that there is tubular reabsorption of allantoin in some individuals. Such a finding is perhaps not surprising for a molecule with such a low molecular weight compared with inulin.

Perhaps the study of a large number of patients with various types of renal lesions would establish certain patterns with respect to the reabsorption of allantoin. It is interesting that the three patients with cardiac failure showed consistently lower allantoin clearances than inulin. On the other hand, two of our patients with more severe renal disease had allantoin clearances that were identical with inulin. All but one of the inulin clearance values which Friedman and his collaborators reported for patients with cardio-renal disease exceeded $80 \mathrm{cc}$. per minute. It is possible that with subjects showing more advanced pathology, these investigators might also have observed larger deviations.

Because of the tediousness and exacting nature of the analytical method for allantoin, there would seem little justification for its use in clearance studies unless it were a reliable glomerular clearance which could be employed under all conditions. In human disease, the allantoin clearance appears to us to have decidedly limited applicability.

\section{SUMMARY}

In the human kidney which has been damaged by nephritis and other pathological conditions, the allantoin clearance does not consistently measure the filtration rate. The results suggest that allantoin undergoes partial tubular reabsorption in some, but not all, diseased kidneys. 


\section{ACKNOWLEDGMENT}

The authors express their thanks to Dr. Allan M. Butler for providing the laboratory facilities required for this study.

\section{REFERENCES}

1. Friedman, M., and Byers, S. O., Clearance of allantoin in the rat and dog as a measure of glomerular filtration rates. Am. J. Physiol., 1947, 151, 192.

2. Friedman, M., Byers, S. O., and Abrahm, P. M., Allantoin clearance as a measure of glomerular filtration rate in man. Proc. Soc. Exper. Biol. \& Med., 1947, 66, 522.

3. Friedman, M., Byers, S. O., and Abrahm, P. M., Renal clearance of allantoin as a measure of glo- merular filtration rate. Am. J. Physiol., 1948, 155, 278.

4. Miller, B. F., Leaf, A., Mamby, A. R., and Miller, Z., Validity of the endogenous creatinine clearance as a measure of glomerular filtration rate in the diseased human kidney. J. Clin. Invest., 1952, 31, 309.

5. Christman, A. A., Foster, P. W., and Esterer, M. B., The allantoin content of blood. J. Biol. Chem., 1944, 155, 161.

6. Young, E. G., and Conway, C. F., On the estimation of allantoin by the Rimini-Schryver reaction. J. Biol. Chem., 1942, 142, 839.

7. Archibald, R. M., Unpublished, described by Forsham, P. H., Thorn, G. W., Prunty, F. T. G., and Hills, A. G., Clinical studies with pituitary adrenocorticotropin. J. Clin. Endocrinol., 1948, 8, 15. 